\title{
On the Development of Arum maculatum from the Seed.
}

\author{
BY \\ RINA SCOTT AND ETHEL SARGANT. \\ With Plate XXV.
}

N April, I895, a large patch of Arum maculatum was noticed by one of us growing on an open common at Instow, in Devonshire. Most of the plants had but one small ovate-shaped leaf above ground. There were no mature plants anywhere in the neighbourhood.

On digging some of these up, it was clear that they were seedlings, though not very young, but each plant was quite distinct from its fellows. One could trace at least two dead tubers of previous years in most cases, though the plants as yet had not produced the characteristic sagittate Arum-leaf.

It seemed worth while to collect some Arum-fruits, in order to study the germination of the seed and generally to test under what conditions the plant is reproduced by seeds and under what by vegetative budding.

Amongst the clumps of mature plants with sagittate leaves a large number of plantlets with ovate leaves are always found. If a clump be dug up, most of these will be found to arise by vegetative budding from the mature tuber (see Fig. Io A), while a few are true seedlings.

[Annals of Botany, Vol. XII. No. XLVII. September, 1898.] 
It was the contrast between the young and the mature forms which suggested the study of the life-history of Arum maculatum from the germination of the seed onward.

In July of the same year the mature plants with their spadices of ripe fruits were watched, and on one occasion a pair of chaffinches were seen to clear off the berries from two of these in half an hour. Further evidence of birds eating these berries is much needed, as many country people say that birds do not touch them. However, Gilbert White, in his Natural History of Selborne ${ }^{1}$, mentions that the thrush scratches out and eats the tubers of Arums from dry banks, and as the tuber is equally pungent and disagreeable to the taste, there seems no reason why birds should not also eat the berries. The disagreeable taste is principally due to the presence of raphides ${ }^{2}$ (see p. 404).

If birds often eat these berries, it will be easy to see how the seeds could have been deposited on the gorse-covered common at a long distance from the parent plants.

Fruits were collected from several ripe spadices, and the seeds sown in flower-pots, as soon as ripe in July. They germinated readily. The earth was disturbed at intervals, and young seedlings in their various stages of germination preserved in spirit.

The growth of the young plants is extraordinarily slow; it is no wonder that the seedling plants have been little noticed, as nothing is to be seen above ground during the first two seasons' growth, and in the third only one ovate leaf shows itself, which at this stage is difficult to distinguish from a leaf of a young plant produced by vegetative budding from the old tubers ${ }^{3}$.

The easiest way of distinguishing them is, perhaps, by the length of the underground part of the petiole, which in a

${ }^{1}$ Letter xv.

${ }^{2}$ Stahl, Pflanzen und Schnecken, Jena, I888, p. 85 .

3 The 'second season' in this paper corresponds to the first season of Rimbach. In England the seeds ripen in July, and germinate in the autumn; whereas in the colder climate of Germany the seeds do not ripen till September, and consequently do not germinate till the spring. 
vegetatively produced plant is as long as the distance from the upper part of the tuber to the surface of the ground, and as the tuber of the mature plant is situated from 10-16 cms. deep, the difference in length between this and the seedling petiole is very material.

In a favourable habitat the majority of the new plants are produced vegetatively, for the Arum is a plant in which the individual becomes very well established, and is to a great extent independent of reproducing itself by seeds.

It will now be necessary to give a more detailed account of the germination of the seed.

The work in this part of the subject has been necessarily slow and laborious, as the material had to be collected at intervals of a month or less for four seasons.

The seed first swells considerably, then the cotyledon emerges from the seed-coats, carrying with it the plumule and radicle (see Fig. I). Even at this stage, reached in January, the hypocotyl below the plumule is enlarged to form the tuber, and is packed with food-material.

The stem-bud, which is situated on the tuber and within the hollow cylindrical cotyledon, consists of two leaves, one quite rudimentary, and a growing point.

In the next stage, represented in Fig. 3, April, I896, both radicle and cotyledon have elongated, and the tuber has doubled its diameter; within the stem-bud a new leaf has appeared, and the bud now contains all the leaves, which will reach maturity during the third season.

In Fig. 4, May, 1896, a rudiment of a fourth leaf, which will not be fully developed until the fourth season, appears.

In Fig. 5, June, 1896 , the radicle shrivels and soon entirely disappears. Shortly before this the cotyledon, carrying the seed-coats with it, has been detached from the tuber, leaving the stem-bud exposed. This process is brought about by the formation of periderm ${ }^{1}$.

$\mathrm{Up}$ to the stage shown in Fig 4 the tuber is covered by

${ }^{1}$ Cf. Parkin, On some points in the Histology of Monocotyledons, Ann. of Bot. June, I 898 . 
a smooth white epidermis. It must be remembered that the insertion of the cotyledon divides the surface of the tuber into two regions. The epidermis covering the lower part is continuous with the outer epidermis of the cotyledon, and ceases abruptly where the primary root begins. The upper part of the tuber is enclosed within the cylindrical cotyledon, and the epidermis which covers it is continuous with that of the inner cotyledonary surface and with the epidermis of the first leaf. The formation of periderm begins in the layer of cells immediately below the epidermis of both regions. Transverse sections through such a tuber as that drawn in Fig. 4 show five or six layers of periderm-cells near the middle of the tuber, and two or three on either side of the zone in which the cotyledon is inserted. These two formations are connected by one or two layers of peridermcells which cut right across the parenchymatous tissues of the cotyledon, just where it is inserted on the tuber. In older seedlings no doubt a greater number of cell-layers is formed.

The two parts often remain in contact with one another for some time, though organically separated. It is often possible to dig them up without shifting them. In the summer new roots are sent out (from four to six in number) from the upper surface of the tuber (Fig. 6). Some of these, generally two, are contractile ${ }^{1}$ (see Fig. 8). We found roothairs produced in clusters near the tips of the contractile roots at this stage, by which, no doubt, they are firmly fixed in the ground. It is clear that without some point of attachment the effect of the contraction would be to draw the tip of the roots up, rather than to pull down the tuber. But measurements show that the tuber actually sinks deeper into the ground, and in this way is at last freed from its discarded cotyledon and seed-coats, which are left to rot nearer the surface.

The result of the contraction of the rootlets is very startling. The tubers when last examined in May (Fig. 4) were only

\footnotetext{
1 Rimbach, Berichte der Deutsch. Bot. Gesell., April, I897; and Prof. F. W. Oliver, Journal of the Royal Horticultural Soc., April, I 898, p. 493.
} 


\section{Arum maculatum from the Seed.}

about $2 \mathrm{cms}$. below the surface. On turning up the soil in October for new specimens, none were to be found, and it was not until the soil had been turned up almost $7 \mathrm{cms}$. that the missing tubers were discovered (Fig. 6). Probably the soil in the flower-pot was looser than it would have been under natural conditions, and this may perhaps have tended to increase the effect of the pull. If a young tuber be replanted near the surface, it will send out new contractile roots, and in a week will regain its normal depth.

With practice it is quite easy to find seedlings in any stage in nature, even when in the winter resting-condition, by learning the exact depth at which they are to be found at the various times of year.

This is the end of the second season's growth; the whole process has up to this time been carried on underground, and no chlorophyll has been formed.

In the following spring the first ovate leaf, with its two scale-leaves, appears above ground (Fig. 7); the tuber continues to grow in size until June, when next year's tuber is formed.

New roots now arise, some of which are contractile. The leaf withers and the tuber is drawn still deeper into the ground, this time shifting its position as a rule from vertical to horizontal.

It is not, at any rate, until the fourth season, and generally later, that the first sagittate leaves are found. The mature flowering plant (Fig. IO) generally bears three sagittate leaves and two scale-leaves, the inflorescence being enclosed in the sheathing petiole of the innermost leaf (Fig. 9).

It will be seen from this description of the seedling-plant, that a vegetatively produced plant arising, as it generally does, from the lower surface of the mature tuber (Fig. Io A), in addition to the advantage of procuring its food-stuff ready made, has a further very great advantage over the plant produced from seed, in starting from the first at its normal depth in the ground. In this way it eliminates the risk of being eaten up by thrushes or scratched up by animals, and also saves itself a large amount of unnecessary expenditure of 
energy in the yearly production of contractile roots for burying purposes. The result is that the vegetatively produced plant flowers much younger than that produced from seed, which rarely flowers before the seventh year.

\section{INTERNAL MORPHOLOGY.}

Any account of the curious second-year seedlings of Arum maculatum would be incomplete without some examination of their anatomy. Certain points in their external morphology must otherwise remain obscure. External characters, for instance, are insufficient to determine either the homology of the tuber, or the way in which the cotyledon is detached from it at the proper age (cf. Figs. 4 and 5). Irmisch ${ }^{1}$, in describing the mature plant, has rightly stated that its tuber represents the stem-axis of the previous year. This cannot, however, be true of a seedling which has just germinated. The tuber of that drawn in Fig. 2 clearly forms part of the main axis, but we cannot tell from inspection whether the stem alone has been enlarged or part of the root as well. And in that part of the tuber which represents the stem there is no external mark to divide the plumule from the hypocotyl. These questions will of course be settled when the course of the bundles in the tuber has been worked out, but we may so far anticipate our results as to say that the tuber does not show complete root-structure until we reach its base, and it may therefore be considered as belonging entirely to the stem. Moreover, the greater part of it represents the axis of the plumule, for the cotyledonary traces do not bend inwards to join the central cylinder for some distance below the insertion of the cotyledon.

The raphides which give the juice of Arum its acrid quality ${ }^{2}$ are abundant in cotyledon, stem-leaves, and in the periphery of the tuber. The cells which contain them are larger than the

1 Irmisch, Zur Morphologie der monokot. Knollen- und Zwiebelgewächse, Berlin, 1850 , p. 164 .

${ }^{2}$ Stahl, Pflanzen und Schnecken, Jena, I888, p. 85. 
surrounding cells, and are nearly filled by dense masses of needle-shaped crystals. Thick-walled secretory sacs are also found in the tissues of the cotyledon and of the older leaves. Occasionally they even occur in the epidermis. On treatment with salts of iron their contents become black, showing the presence of tannin. We have not found tannin sacs accompanying the vascular bundles.

Before passing on to another part of the subject, we may mention a third point in which the anatomical characters of these seedlings throw light on their external form. The contractile roots of older specimens (Fig. 8) are remarkable for the radial elongation of the cells belonging to the inner cortex. The appearance of the central cylinder in transverse section is in no way distorted by the consequent contraction of the whole root, but the cells of the outer cortex are very much crushed and strained ${ }^{1}$. Sections from the ribbed roots of third or fourth year plants show these peculiarities most plainly.

Hitherto we have dealt only with those points in the anatomy of Arum seedlings which serve to complete our knowledge of their external form. For this purpose we have referred briefly to their vascular system. But the detailed study of this system is interesting in itself, and of importance from two points of view, which we will consider separately.

The course of the bundles in the mature tuber of Arum cannot be deciphered. It is always much more difficult to follow the vascular system in a shortened stem than in one which possesses internodes of moderate length. Two other complications render the task impossible in this case. All the bundles of the central cylinder form a continuous vascular girdle at each node. This peculiarity is found in many genera of the Aroideae ${ }^{2}$. But besides this, all the bundles in the tuber anastomose freely with each other. This is the case even with the leaf-traces which are passing downwards through the cortex to enter the central cylinder at one of the

1 Rimbach, 1. c.

${ }^{2}$ De Bary, Comp. Anat., Eng. ed., pp. 268-269.

E. e 


\section{Scott \& Sargant.-On the Development of}

lower nodes. Thus a complicated network is formed in which no ground plan can be recognized.

The formation of a vascular girdle at each node is indicated even in the youngest seedlings we possess (Fig. I). But the bundles which unite these are not completely fused with each other, and can be distinguished throughout their course. The tendency to anastomose is also shown very early. We have found an irregular lateral anastomosis in a seedling no older than that drawn in Fig. 4. No great complications have yet arisen from this cause however, and therefore the course of the leaf-traces can be clearly followed from their entrance into the tuber until they join the central cylinder, as well as the disposition of the bundles in the cylinder itself.

The transition from stem to root in the hypocotyl has been described in very few Monocotyledons. In these plants it takes place as a rule with great abruptness, and it is hardly possible to prepare a series of transverse sections from which the course of the bundles in so short a region can be accurately determined, without the aid of a microtome. In his elaborate researches on the anatomy of this region in Vascular Plants, M. Gérard states that his choice of Monocotyledonous species was much limited by the necessity of using those only which possess a moderately long hypocotyl ${ }^{1}$. In fact, he described but nine species, nor has much been done in this direction since the publication of his paper in $188 \mathrm{I}$. The anatomy of the hypocotyl in any Monocotyledon is therefore worth investigation.

\section{Course of the Bundles in the Stem.}

At the end of the first year, the three leaves which will come to maturity in the following season are fairly well differentiated in the stem-bud. But to understand the vascular system of the tuber we must choose a seedling in which the cotyledon is still present-such a specimen, for

${ }^{1}$ Gérard, Passage de la Racine à la Tige . . . A Ann. d. Sci. Nat., Sér. 6, Vol. xi, Bot., I88I. 
example, as that drawn in Fig. 4. A transverse section passing through the cotyledon and the stem-bud just above the insertion of the latter on the axis, shows the cotyledon as a ring of tissue studded with five vascular bundles. Within it are three concentric rings which represent the three leaves already mentioned. A fourth rudimentary leaf is indeed present, but as it will not come to maturity in the following year, we are not now concerned with its structure.

Each of the two outer leaves displays three bundles, the third shows a single procambial strand representing its midrib. We can trace these seven bundles in a section taken rather lower down, beneath the insertion of the stem-bud but above that of the cotyledon. The position of the bundles in such a section is diagrammatically shown in Fig. II. The cotyledonary bundles are numbered $\mathbf{I}-5$, and of these that marked 3 is the midrib. The circles $A, B, C$ represent the traces of the first leaf ; $a, \beta, \gamma$, those of the second. The midrib of the third leaf is called $l$. In the node next below this internode, the course of the bundles is indicated by the arrows in the diagram. The inmost circle of traces, $\alpha, \beta, \gamma$, bend inwards, and with the midrib $l$, which forks to the right and left, they form an incomplete vascular girdle. The phloem of the four bundles indeed forms a continuous ring, within which are the groups of xylem. These, though extended tangentially, do not yet unite to form a ring; the xylem of the midrib always remains quite distinct from that of the other bundles. The xylem groups of the latter stretch out in a broken crescent fronting the midrib-an arrangement very characteristic of the young node. It is well shown in Fig. I 5 which represents the first node of the young stem.

The node just described is the third of the young stem, and from it arises the first whorl of roots. When the roots are fully formed, as in the seedling drawn in Fig. 6, a section through their insertion shows the formation called by M. Van Tieghem the 'réseau radicifère ${ }^{1}$ '. The xylem as well as the

1 Van Tieghem, Traité de Botanique, 2nd ed., Vol. i, p. 787.

E e 2 


\section{Scott \& Sargant.-On the Development of}

phloem forms a complete circle. This xylem-girdle is thickened at certain points, and on these the central cylinders of the roots are inserted.

Returning to our younger stem (Fig. 4), we pass downwards from the third node into the second internode. In this the bundle $l$ has disappeared, for one of its branches has fused with $\beta$, the other with $\gamma$. Throughout the second internode we have, as shown in Fig. I2, three bundles in the central cylinder which are the direct continuation of the traces from the second leaf, $a, \beta, \gamma$. Surrounding these we have the traces of the first leaf, $A, B, C$, and in a peripheral circle the cotyledonary traces $\mathrm{I}-5$. In the succeeding node-the second of the young stem-the traces $A, B, C$ bend inwards to the central cylinder. The lateral bundles $B$ and $C$ fuse with the lateral bundles $\beta$ and $\gamma$. $a$ forks to right and left, and we again have an incomplete vascular girdle formed. This time, however, it is the xylem of $A$ which is distinct from the rest.

The two branches of $a$ ultimately fuse with $B$ and $C$. Thus on entering the first internode there are only three bundles within the ring of cotyledonary traces. Here, however, the series of sections which we have been following breaks off. A diagram (Fig. 13) can easily be constructed from other examples to show what will take place in the coming node. But it will be more convenient to consider its structure in detail when we deal with the transition from stem to root. This transition begins almost before the formation of the first node, and continues throughout the short hypocotyl.

\section{Transition FROM Stem to RoOT.}

The transition from stem to root in the hypocotyl of Arum maculatum can be most satisfactorily followed in very young seedlings. Even at the age shown in Fig. I, all the bundles of the first internode are clearly differentiated. Fig. 14 is drawn from a section passing through the stem-bud of the youngest seedling in our possession. Only two leaves and a growing point are found within the cotyledon, and the 
second leaf is quite rudimentary. Yet not only are the bundles of the cotyledon well developed, but three procambial strands are already indicated in the first leaf. A little lower down in the axis these strands are better defined, and the structure of the first internode is perfectly clear. The five cotyledonary traces ${ }^{1}$ form a peripheral circle; within them are the three plumular bundles which correspond in position to the traces of the first leaf. But this, as we have seen, is the typical structure of the first internode in much older tubers.

Complete series of sections can be cut through the axis in seedlings of this age without difficulty, and we possess five such sets of transverse sections. All of them begin near the base of the stem-bud and are continued through the tuber into the primary root. Three series are cut through seedlings of the age shown in Fig. I ; two through rather older specimens, corresponding to Fig. 2. The main features of the transition are the same in all these cases, though no two are alike in every detail. Figs. 14 and 15 are drawn from two sections cut from the same axis.

The diagram (Fig. I3) shows that the eight bundles of the first internode form three groups in the succeeding node. But the process is not nearly so symmetrical here as in the second and third nodes. We have five traces entering the central cylinder in place of three, and the transition to root structure begins in the node itself. No part of the hypocotyl therefore shows the characters of a true stem. It will perhaps be easier to appreciate the difficulty of interpretation if we follow the bundles from the first internode through the succeeding node, and the hypocotyl into the primary root in a single instance. We will choose that seedling from which Figs. 14 and 15 are drawn.

It has already been stated that there are eight bundles in the first internode. The five cotyledonary traces lie near the periphery, while the three plumular bundles form a smaller

1 In Fig. I4 the cotyledon shows six bundles. The sixth is more slender than the others, and disappears lower down. This is a common anomaly. 


\section{IO Scott \& Sargant.-On the Development of}

circle within them. The lateral bundles of the plumule are merely procambial strands, but the third is the direct continuation of the midrib from the first leaf, and its xylem is partially lignified. This bundle we will call $A$ to distinguish it from the others, numbering the cotyledonary traces as in Fig. I4.

As we move downwards through the first internode, the cotyledonary traces turn inwards, and at the same time I approaches 2 and 5 approaches 4 . Near the base of the internode the plumular bundles spread slightly outwards until a section is reached in which all the bundles of the internode lie on the circumference of a single circle. They do not long remain separate from each other. The bundle $A$ forks, one bundle fusing with its right-hand neighbour (5), and the other with that on its left hand (1). The two lateral strands of the plumule fuse with 2 and 4 respectively. We have thus five bundles left, corresponding in position with the five cotyledonary traces.

Up to this time all the bundles in the axis have been of the stem-type, the phloem-groups lying outside the xylem and on the same radius. The xylem itself is centrifugal; that is, the protoxylem is internal. But already the transition to a root-structure has begun. The bundles, which now lie close to each other near the centre of the section, have gradually assumed the characteristic appearance shown in Fig. I5. The four lateral bundles form a crescent in front of the midrib. The xylem of the midrib is here, as elsewhere, perfectly distinct from the other xylem-groups. These features, as we have seen, are characteristic of every young node. But the phloem of the midrib $(p h)$ is clearly branching to right and left, and will ultimately join two phloem-groups already partly formed near the horns of the xylem-crescent. A third phloem-group is indicated at the place marked $*$ on Fig. ${ }_{15}$, and it will divide the xylem-crescent into two parts. All the phloem of the central cylinder will finally divide itself among these three groups, leaving none external to the xylem. In this way the alternate arrangement of xylem and 
phloem characteristic of root-structure is attained. It is clear that the root will be triarch.

It would be hopeless to try to follow the 'rotation' of the xylem, the process by which the protoxylem becomes external, in the shapeless groups forming the crescent. But the xylem of the midrib shows it clearly enough. In the particular case we are considering, this group of xylem has assumed the form of a crescent, with the protoxylem-elements in the centre. Each horn is formed of two or three larger vessels (Fig. I5). This little crescent is at first placed symmetrically with reference to the larger one. Gradually, however, it rotates in such a way that one horn at last points outwards, the other directly inwards. It will be seen that in the figure this rotation has already begun; the two larger elements which form the left-hand horn of the xylem-crescent are nearer the periphery of the section than those which form the right-hand horn. Ultimately the two left-hand vessels become completely external, and then die out. In this way the protoxylem-elements ( $p x$, Fig. I 5 ) are left external to the remaining elements of the xylem. While this has been going on, all the bundles of the stele have drawn much closer together, and one or two larger vessels have been differentiated from the conjunctive tissue within them. In this way a xylemplate is formed.

It is clear from this description that the transition from stem to root structure has taken place according to the third type described by M. Van Tieghem ${ }^{1}$. The xylem-groups have remained in situ, 'rotating' through $180^{\circ}$, in order that the protoxylem may become external ; and the phloemgroups have branched to right and left, the adjacent branches of two groups uniting. The branching of the phloem takes place with great regularity in all the specimens we have examined. But it is merely formal to describe the process by which the protoxylem has become external as a rotation. Sometimes indeed, as in the example just described, a partial 


\section{I 2 Scott \& Sargant. - On the Development of}

rotation does take place. It is supplemented by the disappearance of external xylem-elements, and by the formation of new ones within the protoxylem. In other cases no rotation whatever occurs. The xylem-groups are all approaching a common centre during the transition, and the larger elements commonly move inwards more quickly than the protoxylem, thus leaving it external. In every case we have examined, some of the xylem elements die out of each bundle, and a few larger vessels are formed within the stele. Thus in one way or another the protoxylem becomes external during the transition, but never by a simple process of rotation, and often without any true rotation at all.

The four other seedlings from which we have cut complete series of sections show much variation in the structure of the mode. In all, the xylem-group of the midrib remains distinct, and is continued into one of the xylem-groups of the triarch root. The characteristic xylem-crescent is also more or less completely formed opposite the midrib in every case. But in two cases this crescent shows two xylemgroups, in one (besides the example described) it shows four, and in one seven. This last case is remarkable for a still more considerable deviation from the type. The rootstele when first formed is tetrarch, the fourth xylem-bundle corresponding in position to the stem-bundle we have called A. A little lower down, however, this xylem-bundle disappears from the root-stele, and the phloem-groups on either hand of it unite. Thus the root in the end becomes triarch. This variation is probably not uncommon, for in three series of sections through the lower part of the tuber, and the upper part of the root which we have cut through older seedlings, two show a tetrarch structure when the root is first formed. In one of these cases the tetrarch root becomes triarch later on; in the other, the tetrarch structure seems to persist.

We are inclined to consider those cases normal in which three distinct groups of xylem are formed in the first node and are continued downwards into the triarch root. These three 
groups would represent three primitive bundles belonging to the cotyledon, two of which branch immediately on entering the first internode. Thus the symmetry of the root-structure would be immediately derived from that of the cotyledon. The anomalies just described show, however, that one of the plumular bundles may occasionally exercise some influence on the root-structure. We hope to obtain some light on this point from the examination of seedlings belonging to allied genera.

\section{EXPLANATION OF FIGURES IN PLATE XXV.}

Illustrating Mrs. Scott's and Miss Sargant's paper on Arum maculatum.

Abbreviations : s., seed; $t$., tuber; s.l., scale-leaf; $r$., root ; c. $r$., contractile root; $b$, bud.

Fig. I. Arum maculatum. Seedling. Jan. 29, 1896.

Fig. 2. " " " Showing the tuber, radicle, and root-

Fig. 3. " , , A little more advanced. April, I 896.

Fig. 4. " " " 1896.

Fig. 5. " " June 9,1896 . The seed-coats and cotyledon have been cut off by periderm.

Fig. 6. " " $\quad$ Oct. I4, 1896 . The radicle has shrivelled and new roots have been formed.

Fig. 7. " " " Young plant third season.

Fig. 8. " " $\quad$ June 9, I898. Young plant fourth season, showing two contractile roots.

Fig. 9. " " Section through petiole of the innermost leaf of mature plant (Fig. I0), showing the inflorescence enclosed in it and the next year's vegetative bud (b).

Fig. Io " " Mature plant with vegetatively produced young plant $(A)$ attached, and numerous tubers about to form new plants.

Figs. I I, I 2, I3. Diagrams illustrating the course of the bundles in the epicotyle donary stem of a seedling about the age shown in Fig. 4 .

I -4 , Cotyledonary traces.

$A-C$, Traces from first leaf.

$a, \beta, \gamma$, Traces from second leaf.

$l$, Mid-rib of third leaf. 


\section{I4 Scott \& Sargant.-Arum maculatum.}

Fig. I4. Transverse section of stem-bud, passing through the growing point. From seedling of age shown in Fig. I. Six bundles in the cotyledon; one of them - which will disappear later-is very slender. Three bundles in the first leaf.

Fig. I5. Transverse section through central part of hypocotyl, showing transition from stem to root structure. Drawn from same seedling as Fig. I4.

ph., phloem of midrib which is branching to right and left.

$p x$., protoxylem of midrib.

$x, x, x, x$, four groups of xylem forming crescent in front of midrib.

Figs. I-9 are drawn by Mrs. Scott ; Fig. Io by Mr. G. T. Gwilliam; Figs. I I-I 5 by Miss E. Sargant. 
Annats of Botany

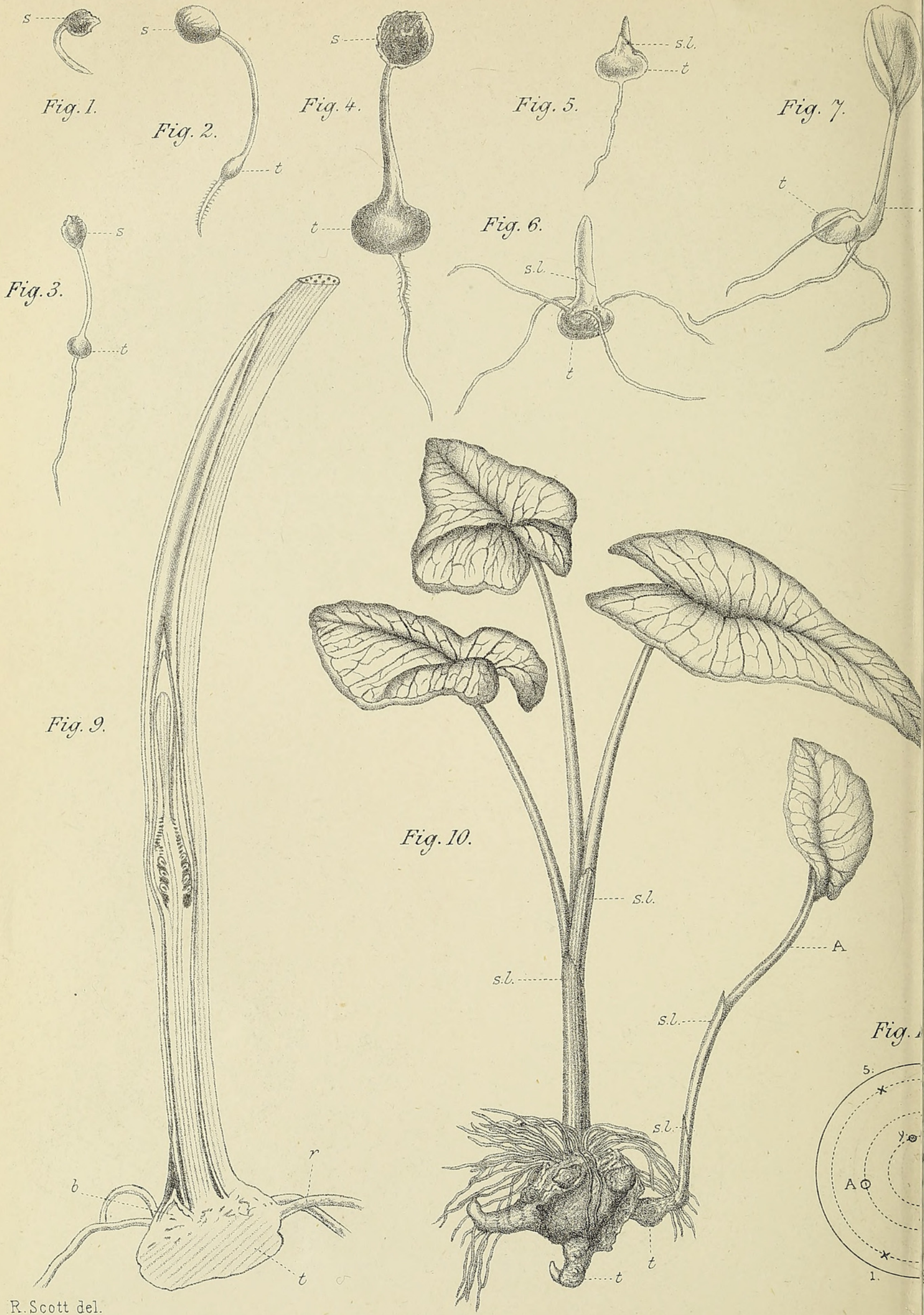

SARGANT AND SCOTT. - GERMINATION OF ARUM. 
Vol.XII, Pl.XXV.
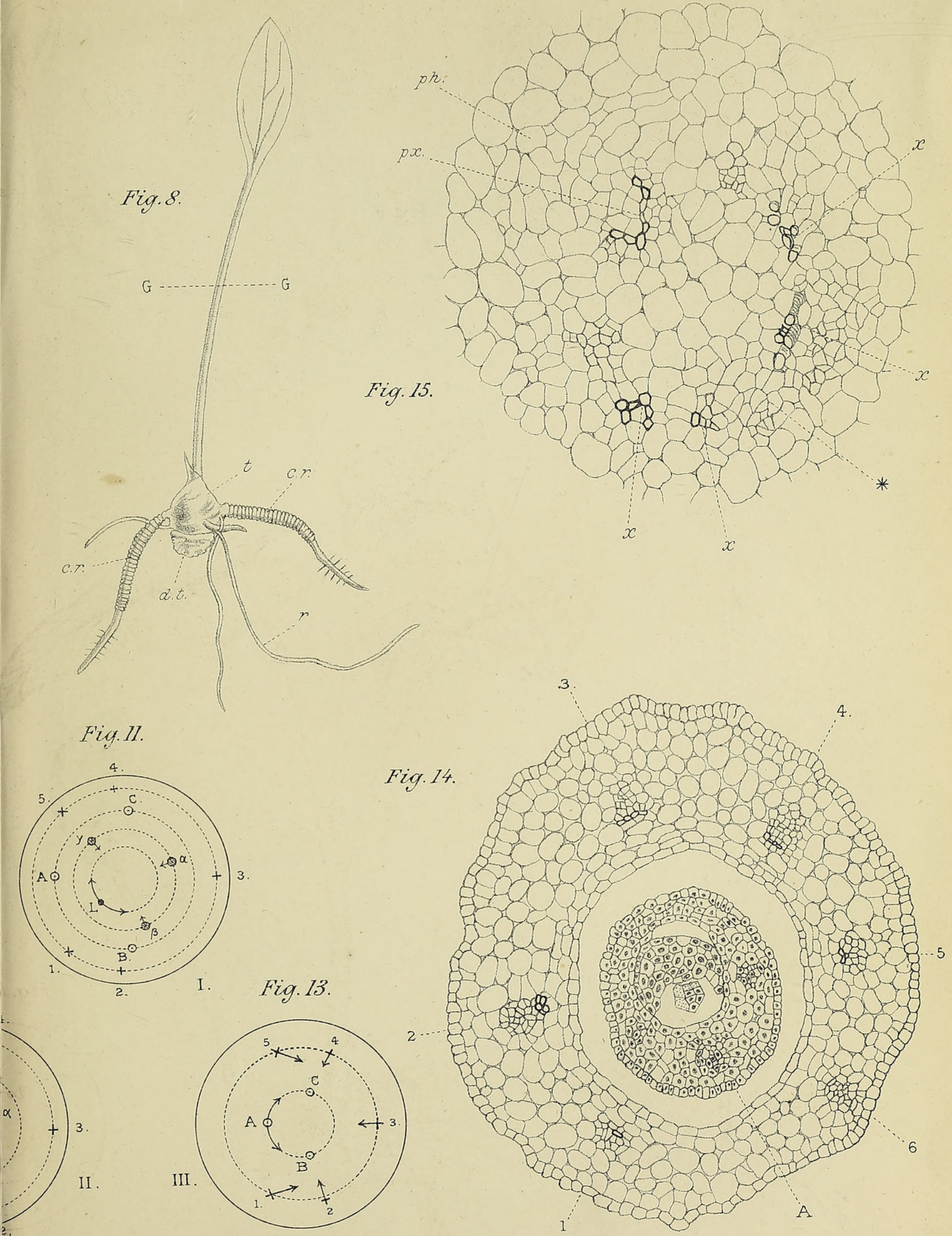

Fig. 13.

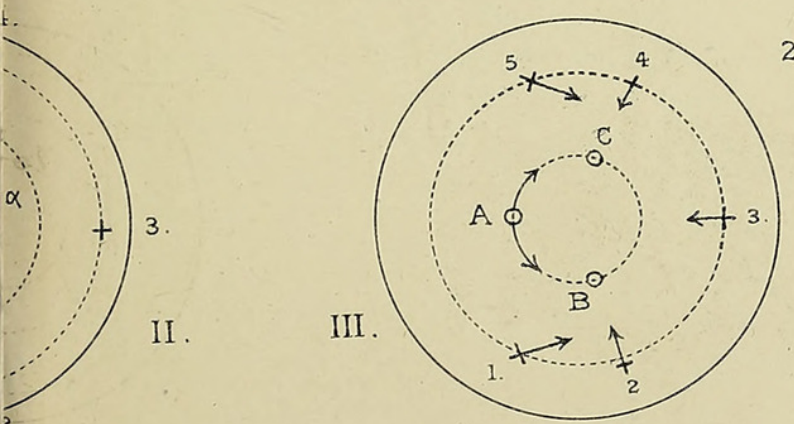

Fig. 14
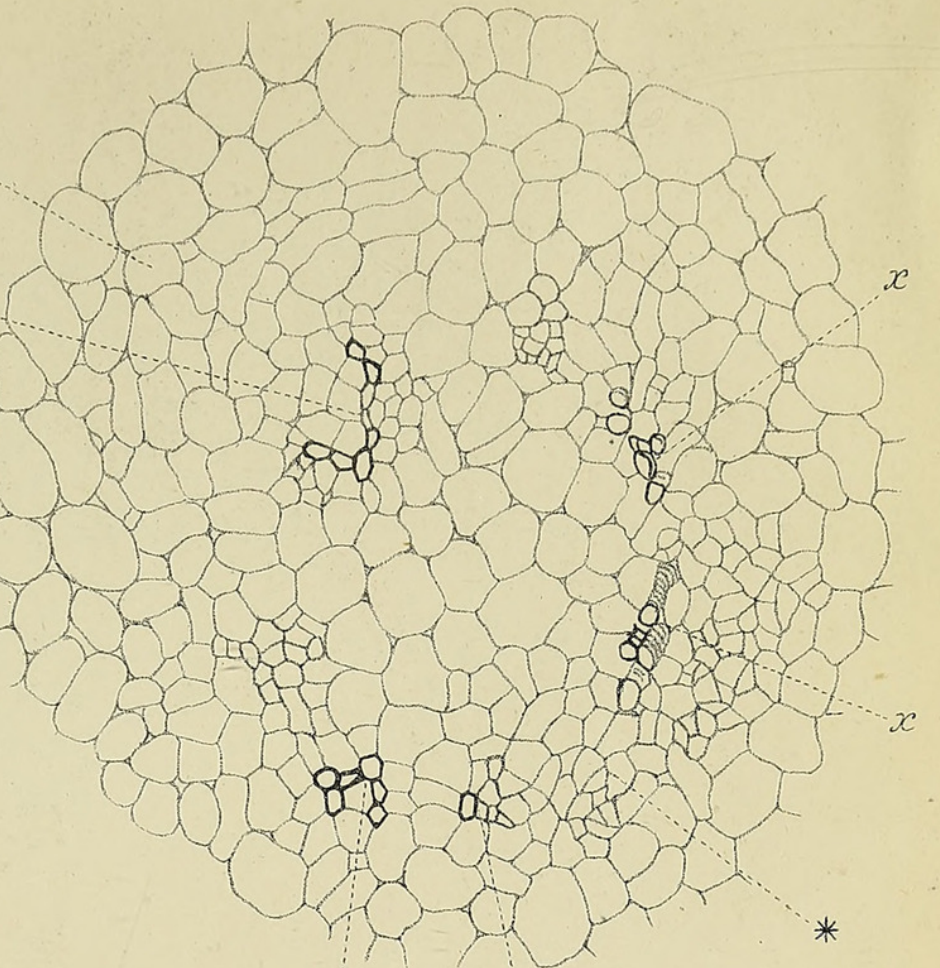

$x$

$x$

University Press, Oxford 


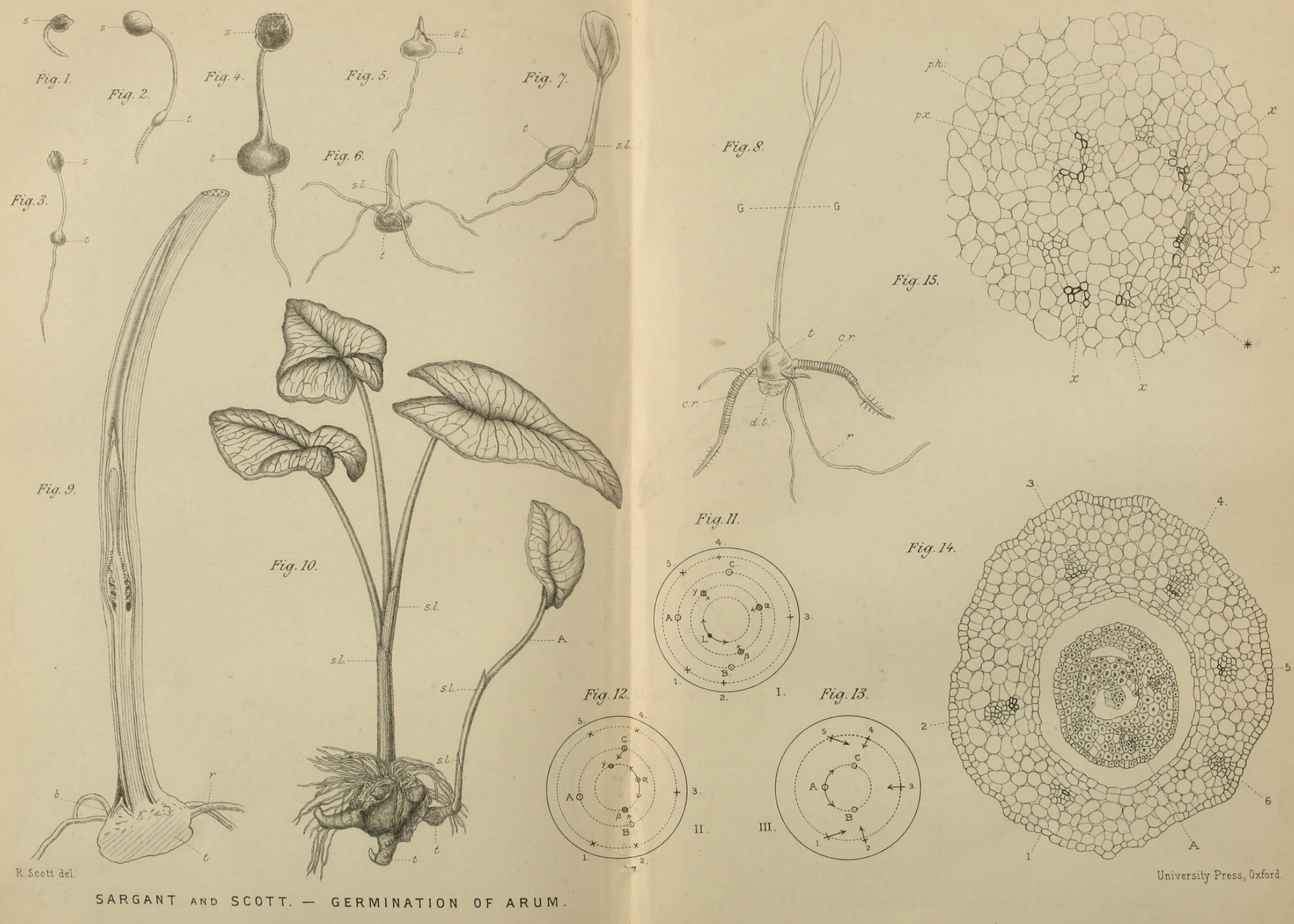




\section{$2 \mathrm{BHL}$ Biodiversity Heritage Library}

Scott, Rina and Sargant, Ethel. 1898. "On the development of Arum maculatum from the seed." Annals of botany 12, 399-414. https://doi.org/10.1093/oxfordjournals.aob.a088700.

View This Item Online: https://www.biodiversitylibrary.org/item/233102

DOI: https://doi.org/10.1093/oxfordjournals.aob.a088700

Permalink: https://www.biodiversitylibrary.org/partpdf/318512

\section{Holding Institution}

Smithsonian Libraries

\section{Sponsored by}

Biodiversity Heritage Library

\section{Copyright \& Reuse}

Copyright Status: Not in copyright. The BHL knows of no copyright restrictions on this item.

This document was created from content at the Biodiversity Heritage Library, the world's largest open access digital library for biodiversity literature and archives. Visit BHL at https://www.biodiversitylibrary.org. 